\title{
Focus on Numélec 2012
}

This topical-Numélec issue, relative to computation of electromagnetic fields, involves selected extended papers which have been presented in the conference Numélec (Marseille - July 2012). Numélec is an international scientific conference on the numerical computation of electromagnetic fields held every 2 years. The first salient feature of the conference is that it gathers the various communities of researchers working on both "low" and "high" frequencies. Though dealing both with Maxwell's equations and their numerical solutions, these communities usually tend to work apart and it is very important to preserve intellectual contacts in order to allow cross-pollination between approaches that are sometimes very different but whose confrontation is so often fruitful. The second salient feature is that the conference is mainly French speaking. Even if English has become the vehicular language of science and engineering, we are convinced that the use of the native language of most of the participants greatly eases a much finer expression of deep ideas. Moreover the persistence of various languages, not only French, in science is an important source of creativity and of richness of thoughts. Numélec 2012 has been organized jointly by the AIM (association des Ingénieurs de Montefiore, Liège, Belgium) and the Institut Fresnel (Unité Mixte de Recherche 7249, AMU, CNRS, ECM, Marseille, France) in Marseille, France on July 3-5, 2012. Ninety-six scientists have attended the event: engineers, physicists and applied mathematicians, and they have presented a wide bunch of contributions including industrial applications and new computational methods. The papers presented in this issue reflect the wide range of applications of computational electromagnetic that nevertheless share a hard core of common know how in numerical methods. 